BULLETIN Bulletin hispanique

HISPANIQUE Université Michel de Montaigne Bordeaux

118-1 | 2016

La Guerre Civile espagnole aujourd'hui (1936-2016)

\title{
Las madrinas de guerra en la Guerra Civil
}

\section{Manuel de Ramón Carrión}

\section{OpenEdition}

\section{Journals}

Edición electrónica

URL: http://journals.openedition.org/bulletinhispanique/4284

DOI: 10.4000/bulletinhispanique.4284

ISSN: $1775-3821$

\section{Editor}

Presses universitaires de Bordeaux

\section{Edición impresa}

Fecha de publicación: 15 julio 2016

Paginación: 157-174

ISBN: 979-10-300-0058-0

ISSN: 0007-4640

\section{Referencia electrónica}

Manuel de Ramón Carrión, « Las madrinas de guerra en la Guerra Civil », Bulletin hispanique [En línea] 118-1 | 2016, Publicado el 15 julio 2019, consultado el 10 diciembre 2020. URL : http://

journals.openedition.org/bulletinhispanique/4284; DOI : https://doi.org/10.4000/bulletinhispanique. 4284 


\title{
Las madrinas de guerra en la Guerra Civil
}

\author{
Manuel de Ramón Carrión \\ Universidad Complutense de Madrid - España
}

En Espagne, les marraines de guerre sont presque tombées dans l'oubli, bien qu'elles aient été très populaires durant la Guerre Civile. L'article analyse ce dispositif particulier, créé pour relever le moral des troupes. Les différences entre les marraines des deux camps sont signalées, en raison notamment de l'importance que les autorités franquistes leur ont accordée. Enfin, l'article explore les origines du phénomène.

Mots-clés: marraines de guerre, soldats, Guerre Civile, Guerre mondiale, Histoire des femmes

En Espańa, la figura de la madrina de guerra ha quedado casi en el olvido a pesar de la gran popularidad que alcanzó durante la Guerra Civil. El artículo analiza este peculiar instrumento utilizado para prestar apoyo moral a los combatientes. Se establecen las diferencias entre las de una y otra zona, especialmente si se tiene en cuenta la importancia que las autoridades franquistas les concedieron. Asimismo, se rastrean los orígenes del fenómeno.

Palabras clave: madrinas de guerra, soldados, Guerra Civil, Guerra mundial, Historia de las mujeres

In Spain, the figure of the «soldier's wartime penfriend» has been almost forgotten despite their great popularity during the Spanish Civil War. This article analyses this particular instrument created to provide moral support to the fighters. It also examines the differences between the two sides, with special attention to the importance that the pro-Franco authorities granted them. Moreover, the article studies the origins of this tradition.

Keywords: godmothers of war, soldiers, Civil War, World war, Women history. 
D ara muchos autores, la Primera Guerra Mundial representó el comienzo 1 de la industrialización de la guerra. A partir de 1914 ya no bastaba con el imprescindible valor de los soldados y la habilidad de los generales para vencer. Estos factores pasaron en cierto modo a un segundo plano frente a la potencia destructiva de las nuevas armas. Es decir, frente a la potencia industrial y económica de los países contendientes.

Sin embargo, la Gran Guerra también aportó otras novedades con un carácter que podríamos calificar de humanitario, como la mejora de la sanidad militar o el esfuerzo por enterrar dignamente a los caídos. En este segundo caso, podría hablarse de un intento por mantener alta la moral del soldado, ya que al menos a los combatientes les podía reconfortar el hecho de saber que si morían su cadáver sería enterrado de forma respetuosa en una tumba individual en la que constaría su nombre.

La preocupación por la moral del soldado originó también otras iniciativas como la creación de la figura de la «Madrina de Guerra» con la que numerosas mujeres mantenían correspondencia con soldados que estaban en primera línea a los que también enviaban regalos. En un principio, las madrinas atendieron sobre todo a los militares que no podían establecer comunicación con sus familias porque estaban en las zonas ocupadas por los alemanes. De esta forma, los soldados no se sentían tan solos. En el caso de la Guerra Civil española esta función era esencial, puesto que la línea del frente entre republicanos y franquistas dividió también a muchas familias que no se podían comunicar y así lo entendieron las autoridades de Burgos.

Hasta el momento no hemos encontrado registros que sitúen la aparición de esta peculiar figura en conflictos anteriores a 1914. Mientras no existan pruebas documentales que demuestren lo contrario, hemos de pensar que surgió en la Gran Guerra. Incluso ya hay datos que parecen situarlo en 1915, como veremos a continuación.

El objetivo estaba muy claro. Incluso puede afirmarse que era doble. Por un lado, se trataba de ayudar a los soldados a mantener el ánimo en los momentos más difíciles porque sabían que en la retaguardia había una joven que rezaba y pensaba en él. El segundo objetivo era el de establecer una conexión entre el frente y la retaguardia, que tan a menudo era despreciada por quienes padecían todo tipo de privaciones enfangados en una trinchera y en constante peligro de morir. En definitiva, se trataba de establecer un lazo de unión entre los militares y la sociedad civil: «De hecho -apunta Verónica Sierra-, llegó a ser considerado algo extrańo que un soldado no contase con una madrina o con varias, como ocurrió en muchas ocasiones ${ }^{1} »$.

En España podemos considerar que las primeras madrinas de guerra aparecen en la década de 1920, durante la guerra de Marruecos. Así parecen atestiguarlo algunas pequeñas piezas literarias, entre otras una comedia de Miguel Mihura²,

1.Verónica Sierra, Aprender a escribir cartas. Los manuales epistolares en la España contemporánea (1927-1945), Gijón, Ediciones Trea, 2003.

2. Miguel Mihura, La Madrina de Guerra. Comedia en dos actos, Editorial Viuda e hijos de 
y otros sencillos documentos como el anuncio del 10 de octubre de 1924 publicado en El Noticiero Extremeño, en el que el apellido "Bala» podría tratarse de un seudónimo:

Madrina de guerra.- Nos escribe solicitando madrina de guerra el sargento de la primera compañía del batallón expedicionario de Castilla número 15, que se encuentra en Tetuán, don José Bala López ${ }^{3}$.

\section{La Primera Guerra Mundial, origen de las madrinas}

Las primeras referencias que hemos podido constatar proceden sobre todo de Francia, así como de Bélgica, Quebec y algunas de Italia. En la revista Le Figaro Histoire, C. Lestienne establece el mes de enero de 1915 como fecha del surgimiento de esta «institución» de inspiración católica orientada a sostener la moral de los soldados, especialmente de los que tenían a sus familiares en las regiones del Norte y del Este que habían sido ocupadas por los alemanes: «Afin de soutenir le moral des soldats des régions occupées, l'institution des marraines de guerre est crée en janvier $1915 \Perp^{4}$.

Según Lestienne, la idea surgió de la asociación «La famille du soldat», seguida después por «Mon soldat», y contó con el apoyo del ministro de la Guerra, Alexandre Millerand. Las madrinas eran «damas de buena sociedad». Rápidamente, numerosos diarios y publicaciones colaboraron como puente entre las asociaciones de ayuda a los soldados y las jóvenes que querían ser sus madrinas. Entre otras, podemos destacar la revista revista humorística La vie parisienne, donde los militares ponían anuncios solicitando madrinas de guerra.

Es cierto que durante la Primera Guerra Mundial muchas mujeres cambiaron las tareas teóricamente femeninas para trabajar como munitionettes (obreras de las fábricas de armamento). Sin embargo, la prensa y la literatura destacaron más los papeles tradicionales, como el de enfermera, dama de la caridad o madrina de guerra.

En las trincheras, los poilus franceses sobre todo encontraron una forma amable de evadirse de la espantosa realidad que les rodeaba escribiendo a una desconocida. Cabe pensar que hablarían de la situación en el frente. Aunque no es posible saber si describirían con detalle a su madrina las espantosas carnicerías que presenciaban a su alrededor, seguramente les hablarían de lo que sońaban hacer cuando terminase el conflicto.

R. Velasco. Madrid, 1922.

3. Manuel de Ramón y Carmen Ortiz: Madrina de Guerra. Cartas desde el frente, Editorial La Esfera de los Libros, Madrid, 2003, p. 54.

4. Camille Lestienne: "Des marraines de guerre pour les soldats (1915)», Le Figaro Histoire, (28/08/2014) http://www.lefigaro.fr/histoire/centenaire-14-18/2014/08/22/2600220140822ARTFIG00065-des-marraines-de-guerre-pour-les-soldats-1915.php (consultado el 29 de junio de 2015).

5. Esta asociación fue creada por Marguerite De Lens el 11 de enero de 1915. 
Y seguramente también les pedirían unos regalos tan preciados para ellos como el tabaco, una pipa, embutidos, calcetines de lana y jerseys. Objetos muy valiosos para unos hombres que carecían de casi todo. Algunos enviaban a cambio lo que podría denominarse como "artesanía de guerra»: pequeñas figuras que tallaban con la navaja en trozos de madera o en los casquillos de los proyectiles y que hoy podemos contemplar en museos y casas particulares.

No todo fue artesanía, algunas afortunadas madrinas también recibieron poemas que han entrado en la historia de la literatura francesa. La poetisa Yves Blanc ${ }^{6}$ recibió un poema de su ahijado Guillaume Apollinaire, a quien había conocido durante un viaje en tren:

\section{Para Y.B.}

Aunque me llegó en agosto su cuarteto de abril Me ha librado de todo mal y de toda herida Su dulzura me persigue en toda mi aventura

Durante este ańo, oscuro como el mil. Yo os lo agradeceré si es posible, lo aseguro Cuando venzamos al alemán cobarde y vil De cuya injuria la virtud francesa ha sido victima. [Poemas a la madrina]

La correspondencia entre Apollinaire e Yves Blanc fue recopilada en el libro Lettres à sa marraine, publicado en los ańos 1950. En 1999, los originales de las cartas fueron vendidos en París por unos 60.000 euros. En su misiva del 5 de diciembre de 1915, Apollinaire afirmaba:

Je suis depuis six jours déjà dans la tranchée de première ligne dont l'horreur ne se peut décrire, encore moins imaginer. De ces abîmes blancs, pleins d'eau, arrosés par la pluie métallique et puante des plus redoutables engins de guerre, je vous envoie le témoignage affectueux de mon amitié pour vous ma petite marraine, bien apprise ${ }^{7}$. [firmado G. de Kostrowitsky]

Apollinaire mantuvo también correspondencia con Madeleine Pagès, que era su novia oficial, y con su amante, Louise de Coligny-Châtillon, una aristócrata casada. El libro Lettres à Lou', recopila la correspondencia con esta última:

\section{Les soldats s'en vont lentement}

Dans la nuit trouble de la ville.

6. Yves Blanc era el seudónimo de la poetisa francesa Jeanne Burgues, autora de la novela Histoire de la Maison de l'Espine.

7. Ya estoy en la trinchera de la primera linea desde hace seis dias. El horror no se puede describir, todavia menos imaginar. Desde estos abismos blancos, llenos de agua y regados por la lluvia metálica $y$ hedionda de los más temibles ingenios de guerra, le envio el testimonio afectuoso de mi amistad para usted, mi madrinita querida. (Traducción libre del autor de este artículo).

8. Guillaume Apollinaire: Lettres à sa marraine 1915-1918, Introducción y notas de Marcel Ademà, París, Gallimard, 1979, p. 58.

9. Guillaume Apollinaire: Lettres à Lou, Prefacio y notas de Marcel Décaudin, París, Gallimard, 1990, p. 157. 
Entends battre mon coeur d'amant.

Ce cour en vaut bien plus de mille

Puisque je t'aime éperdument ${ }^{10}$.

En 1916 Apollinaire fue herido en la cabeza, en noviembre de 1918 falleció en París víctima de la gripe, pocos días antes de la firma del Armisticio. Wilhelm Apollinaris de Kostrowitsky, Guillaume Apollinaire para la historia de la Literatura Universal, se convirtió en uno más de los 525 escritores franceses que sucumbieron en la Primera Guerra Mundial. A esta cifra habría que sumar las muertes de numerosos pintores y músicos de ambas zonas.

Otros escritores y artistas franceses también tuvieron madrina de guerra. El poeta bretón Jean Pierre Calloc'h (Yann Ber Kalloc'h) mantuvo correspondencia con madame Alleno, de la que apenas se conocen datos. Calloc'h murió en 1917. Entre sus ropas se encontró una carta profética:

En medio de un descampado, en un agujero recubierto con una chapa, bajo la cortina de acero de los cañonazos. Le escribo apoyado en las rodillas. Hace mucho frío, llueve y nieva y no tenemos fuego. Éste es el país de la miseria y del dolor (...)

Debemos atacar sin demora. Iremos porque es preciso. Y esto puede ser un adiós ${ }^{11}$.

En una carta mucho menos dramática, fechada el 18 de septiembre de 1915, el también escritor Henri Barbusse mostraba su agradecimiento a Jeanne Charrot:

Mi querida madrina,

Ya tengo la pipa. Me ha llegado en una cajita junto con el tabaco que poco a poco absorberá. ¡Esta pipa me parece simplemente perfecta! ${ }^{12}$.

Al comienzo de este epígrafe se mencionaba la presencia de madrinas de guerra québecoises que se cartearon sobre todo con sus paisanos. En 1996 se publicó la correspondencia de Paul Norac (seudónimo de Paul Caron, periodista de Montmagny, muerto en 1917), donde aparecen las cartas de Henriette Bourassa Chauvin, a quien eligió como madrina en 1914.

El músico Maurice Ravel, que con 39 años también combatió en la Primera Guerra Mundial, dedicó el minueto de su obra Le tombeau de Couperin a Jean Dreyfus, el hijo de su madrina caído en el frente. Desconocemos si también tuvo como madrina a la bailarina y actriz rusa Ida Rubinstein, a la que años más tarde dedicaría su conocido Bolero.

10. Los soldados se alejan lentamente

En la turbia noche de la ciudad

Escucha palpitar mi corazón de amante

Este corazón vale por mil

Porque te amo locamente (Traducción libre del autor de este artículo).

11. Jean Pierre Calloc'h, «Dernière lettre sans adresse, écrite le jour de sa mort et retrouvée sur lui» (10 de abril de 1917), en http://calloch.jp.free.fr/Pages/dern_let.htm (Traducción libre del autor de este artículo).

12. Henri Barbusse, Le feu Journal d’une escouade, París, Flammarion, 1992. 
Ida Rubinstein fue una excéntrica madrina de militares franceses en las dos guerras mundiales. En 1914 fundó un hospital auxiliar y se convirtió en enfermera voluntaria. Coco Chanel le diseñó una cofia de estilo egipcio. Al parecer, acudía al frente en coches de lujo, acompañada de sus criados para visitar a los heridos, a los que animaba con champán.

Cuando los nazis invadieron Francia en la Segunda Guerra Mundial, Ida Rubinstein, de origen judío, huyó a Inglaterra. En Londres se convirtió en la madrina de los pilotos franceses de la escuadrilla "Alsacia», encuadrada en la RAF.

\section{Aproximación al papel de las mujeres en la Guerra Civil española}

Con la llegada de la República, los movimientos feministas espańoles recibieron un fuerte impulso. Pese a los recelos machistas de la época, los partidos de izquierda y los sindicatos apoyaron las reivindicaciones de la mujer. La nueva Constitución instauró el sufragio universal gracias a la diputada Clara Campoamor, que se enfrentó a las izquierdas, siempre temerosas de que las mujeres votasen a los partidos de derechas.

A lo largo de los 40 ańos transcurridos desde que murió el dictador, los abundantes trabajos historiográficos realizados sobre el papel de las mujeres en la Guerra Civil ${ }^{13}$ permiten albergar ya pocas dudas acerca del papel secundario que, salvo excepciones, desempeñaron tanto en la retaguardia como en el frente. $\mathrm{Si}$ bien es preciso tener en cuenta algunos importantes matices que podemos observar en cada zona contendiente e, incluso, en los distintos momentos del conflicto.

Es sobradamente conocido que al comienzo de la guerra, muchas mujeres estuvieron en primera línea vistiendo el famoso mono azul de milicianas de la República, aunque también sabemos que por lo general su presencia en

13. El abundante número de investigaciones al respecto impide que hagamos una relación exhaustiva de los mismos, pero hemos escogido una breve selección:

Aguilera Sastre, J. (2007), «1931: las mujeres españolas ante la República» en Cuadernos Republicanos, $\mathrm{n}^{\circ} 64$.

Carabias, M. (2001), Rosario Sánchez Mora, la dinamitera, Ediciones del Orto, Madrid.

Casanova, M. (1996), La diplomacia española durante la guerra civil, Ministerio de Asuntos Exteriores, Madrid.

De La Mora, C. (2006), Doble esplendor. Autobiografía de una aristócrata española, republicana y comunista, Gadir, Madrid.

Morcillo Gómez, A. (2007), «Feminismo y lucha politica durante la II Republica y la Guerra Civil» en Folguera, P. (coord..), El feminismo en España: dos siglos de historia, Editorial Pablo Iglesias, Madrid.

Scarzanella, E. (2008), «Il pipistrello e la colomba: le femministe spagnole Clara Campoamor e Isabel de Palencia in esilio in Argentina e in Messico", Rivista telemática di studi sulla memoria femminile, DEP, $\mathrm{n}^{\circ} 28$.

Taillot, A. (2009), «A prueba del tiempo: las intelectuales antifascistas españolas entre silencio oficial y lucha por la memoria», Historia Actual on-line, n 19. 
la zona de combates fue casi testimonial y duró hasta septiembre de 1936. La imagen de la mujer en las trincheras republicanas se utilizó más con fines propagandísticos para animar a la población a luchar contra los sublevados que con fines militares.

$Y$ esto no debe interpretarse de forma peyorativa, puesto que la propaganda es una de las armas más importantes en cualquier guerra desde que los seres humanos comenzaron a matarse entre sí. En la zona franquista no hubo mujeres en primera línea y la figura femenina más destacada fue Pilar Primo de Rivera, si bien su capacidad de adoptar decisiones importantes fue casi nula.

Si dejamos de lado el aspecto meramente militar, podemos encontrar en la zona gubernamental esas excepciones a las que antes nos referíamos. Hasta no hace mucho se pensaba que las mujeres republicanas no habían desarrollado actividades políticas relevantes durante la guerra salvo Dolores Ibárruri, Federica Montseny o Victoria Kent entre otras. Por el contrario, Mónica Moreno afirma que hubo un grupo de mujeres que participaron activamente en la vida republicana, aunque con sentimientos encontrados:

La militancia de estas mujeres en el republicanismo, el feminismo y el pacifismo adopta en la guerra civil una nueva fisonomía: son republicanas que se identifican con un proyecto cada vez más desdibujado -aunque no para ellas-, feministas que aceptan dar prioridad a la victoria sobre la emancipación femenina y pacifistas que defienden el derecho del gobierno que consideran legítimo a defenderse con las armas. $\mathrm{Y}$ algunas, pocas, que se niegan a ser encuadradas con las anteriores. Esta pluralidad, no sólo política sino también ante la guerra, rompe con estereotipos y ofrece una visión compleja de las relaciones entre mujeres, guerra y republicanismo ${ }^{14}$.

Incluso en el campo de la diplomacia republicana hubo mujeres, como Isabel de Palencia (Isabel Oyarzábal), que fue la primera embajadora de la historia de España como ministra plenipotenciaria de la República en Suecia y los países nórdicos. También fue delegada en la Sociedad de Naciones e intervino en la Organización Internacional del Trabajo ${ }^{15}$.

En este sentido, también es notable el papel que algunas periodistas desempeñaron al servicio de la República. Eiroa y Sanmartí destacan que numerosas periodistas de la zona republicana se pusieron al servicio del Gobierno legalmente constituido:

The outbreak of the Civil War intensified the role of women journalists as they became completely committed to the struggle against the forces of the military rebels. This was the moment when many of them decided to go out onto the streets to defend the freedoms they had gained with the arms they had available: the pen and the word. Their radio speeches, reports, chronicles or published interviews in various rearguard media, or the contributions sent from the front, altogether form a testimony to their important contribution to the Republican cause ${ }^{16}$.

14. Mónica Moreno, «Republicanas y República en la Guerra Civil: Encuentros y desencuentros", Ayer. Revista de Historia Contemporánea, núm. 60, 2005, pp. 166-195.

15. Matilde Eiroa, Isabel de Palencia, Universidad de Málaga, 2014.

16. Matilde Eiroa y Josep Maria Sanmartí, «Also in the newspapers: Spanish Women in 
Como se ha dicho, en la zona franquista la política más destacada fue Pilar Primo de Rivera, hermana del fundador de la Falange, pero su trabajo podría calificarse como auxiliar, porque se centró en el encuadramiento de las mujeres de la retaguardia. Entre estas labores figuraría sin duda la promoción de las madrinas de guerra.

Desde el comienzo del conflicto, las mujeres que estaban en el territorio nacionalista quedaron relegadas al papel "propio de su sexo" que impondría más tarde el Nuevo Estado. Un papel de madre y esposa ejemplar que tras la boda se había convertido nuevamente en una menor de edad.

En esta situación, la aportación femenina al esfuerzo bélico en la zona franquista se limitaba a labores de enfermería, postulantes del socorro al soldado, los trabajos en las fábricas y también como madrinas de guerra. Estas últimas eran mujeres que se dedicaban a mantener correspondencia con los soldados en el frente; sobre todo con aquellos cuyas familias habían quedado en la zona republicana y se sentían especialmente solos. Algunas combinaron las funciones de enfermeras y madrinas de guerra, como Carmen Sánchez en Sevilla, protagonista del libro Madrina de Guerra ${ }^{17}$.

Una vez consolidados los golpistas en su zona, las asociaciones de mujeres y los partidos sólo sobrevivieron en el territorio republicano. En el que estaba controlado por los sublevados, los partidos, sindicatos y organizaciones ciudadanas de izquierdas fueron suprimidos. Incluso los partidos de derechas también desaparecieron y parte de sus militantes se integraron en la Falange. Las organizaciones conservadoras de mujeres fueron absorbidas de forma paulatina por la Sección Femenina, como por ejemplo las «margaritas» de los requetés navarros. Esta asociación se mantuvo independiente hasta la unificación de falangistas y requetés en 1937 como Falange Española Tradicionalista, FET y de las JONS ${ }^{18}$.

M. A. Barrachina afirma que, en un principio, los militares permitieron que la organización falangista impulsase una imagen más activa y militante de la mujer frente a las asociaciones confesionales, asumiendo así los derechos reconocidos por la República, pero sólo fue una táctica para aprovechar las ansias de realizar tareas fuera del hogar ${ }^{19}$. Enseguida se planteó la vuelta de las mujeres junto al fogón para que se olvidasen de sus derechos.

\section{MaDRINAS DE GUERRA EN LA ZONA NACIONALISTA}

Como se ha dicho, y de forma coherente con el papel que concebían para la mujer española después de la guerra, las autoridades franquistas no les

defense of the 2nd Republic», Observatorio (OBS) Journal, vol. 5-n 3, 2011, p. 11.

17. M. de Ramón y C. Ortiz, Ibidem.

18. Francisco Carrionero, A. Fuentes, Ma Sampedro y Ma Velasco, «La mujer tradicionalista: las Margaritas", en III Jornadas sobre Las Mujeres y la Guerra Civil Española, Instituto de la Mujer, Salamanca,1989, pp. 188-201

19. Marie Aline Barrachina, «Ideal de la Mujer Falangista. Ideal Falangista de la Mujer», en III Jornadas sobre Las Mujeres y la Guerra Civil Española, Instituto de la Mujer, Salamanca, 1989, pp. 211-217. 
concedieron ninguna oportunidad de participar en la lucha en el frente. Su contribución a la causa se limitó a permanecer en la retaguardia desempeñando labores auxiliares: cosieron uniformes, sirvieron en los comedores infantiles, fueron postulantes para la ayuda a los soldados, visitaron a los heridos y se convirtieron en enfermeras ${ }^{20}$. En definitiva, trabajos representativos de la figura de madre y esposa impuesta por la ideología imperante, que la calificaba como «fundamental» para apoyar a los hombres que arriesgaban su vida por la Patria.

Las madrinas de guerra representan un papel voluntario, absolutamente femenino, pero a la vez constituyen un "arma» esencial para apoyar moralmente a los combatientes. Un papel que sólo podía realizar una «mujer de su casa». Las jóvenes madrinas enviaban un mensaje implícito: cuando los ahijados recibían su carta podían crearse la ilusión de que estaban hablando con una amiga en la misma trinchera, allí donde sólo había muerte, miedo y privaciones.

En la zona franquista constituyeron una especie de institución semioficial que encarnó el apoyo de los civiles a los militares. Una conexión directa entre el frente y la tantas veces denostada retaguardia, donde según la opinión de los combatientes se comía bien, no hacía frío ni calor, había diversiones y, sobre todo, no existía el peligro. Con las cartas de las madrinas la retaguardia expiaba esos pecados y demostraba que desde la distancia no se olvidaba de los héroes de la primera línea.

Las muchachas no sólo enviaban cartas. En ocasiones, y dependiendo de su capacidad económica, también mandaban los regalos que más podían desear sus ahijados como tabaco, jerséis, mantas, calcetines de lana, embutidos, periódicos y, por supuesto, medallas religiosas y escapularios con el famoso Detente Bala.

Es posible que la idea de escribir a muchachos desconocidos que se encontraban en peligro surgiera de forma espontánea en las jóvenes, aunque también podría ser fruto de la imitación de otras amigas. Las autoridades del gobierno de Burgos estimulaban a las madrinas y les daban facilidades para cumplir su misión. La correspondencia con el frente era gratuita, los periódicos de la retaguardia y, por supuesto, el semanario La Ametralladora (precursor de La Codorniz) publicaban numerosas peticiones de correspondencia de militares y ofrecimientos de las chicas. Unos anuncios que firmaban con seudónimos tan extravagantes como Pedro Matapiojos, Tarzán de las ratas o Manso el Furioso. Por su parte, las jóvenes se apodaban Sonsoles Tomate Verde, Sonsoles Quita Penas o La Panoli num.1.

Pilar Santamaría explicaba en sus memorias la misión de la madrina, que constituía una labor patriótica mitad consuelo y mitad ilusión para el soldado:

Las madrinas de guerra eran como una obligación moral, dulce y femenina ¿Qué más indicado para nosotras que consolar, animar, llevar a los soldados del frente un poco de optimismo y de ilusión? Ellos que luchaban, que estaban a la intemperie, bajo las estrellas, que cuando mirasen al cielo, creyesen que sus parpadeos les enviaban

20. Carmen Domingo, Con voz y voto. Las mujeres y la política en España (1931-1945), Lumen. Barcelona, 2004, p. 231. 
recuerdos y sonrisas ¡Qué labor tan bonita y humana! La madrina era para el soldado un consuelo, una ilusión. (...) ¡Qué contento se ponía aquel soldadito huérfano, que no encontraba para sus penas más que el aliento en las cartas de su madrina ${ }^{21}$.

Esta descripción del papel de la madrina coincide con la visión de los propios soldados. En Madrina de Guerra. Cartas desde el frente, se han transcrito las 122 cartas que Carmen Sánchez conservó. Uno de sus 30 ahijados, el teniente Mariano Clavero resumía su concepto de las madrinas:

Porque la madrina no la concibo de otro modo: un poquitín madre; otro poquito de hermana de la caridad; otro poquillo novia; y un $90 \%$ de amiga leal [27 de septiembre de 1938$]^{22}$.

Una vez que aceptaban a la madrina, los corresponsales se encargaban de recordarle periódicamente las obligaciones que habían contraído con ellos. Eran muy conscientes de sus derechos, como demuestra el propio Mariano Clavero en la carta del 9 de septiembre de 1938 con una poética relación de los deberes de la madrina, que recuerda las obras de caridad cristiana:

Porque eres tú, por el cargo que te has impuesto, la que tiene que derramar la misericordia sobre mí; consolar al triste; dar de comer al hambriento y beber al sediento de afecto, enseñar al que no sabe lo que pasa por ahí; redimir al cautivo del tedio y enterrarlo si lo matan al ahijado y rezarle una oración [9 de septiembre de 1938 ${ }^{23}$.

Según Florentino Rodao ${ }^{24}$, Jaime Milans del Bosch y otros oficiales franquistas solicitaron madrinas de guerra japonesas en el periódico Asahi Shimbun con unos anuncios insertados en 1937 por José del Castillo, representante diplomático del Gobierno de Burgos en Tokio. Rodao asegura que la correspondencia de las jóvenes japonesas fue remitida a la Séptima Bandera de la Legión y al crucero Baleares, aunque no comenta nada sobre el idioma en que se comunicaron los militares españoles y sus madrinas niponas.

\section{LAS MUJERES REPUBLICANAS, UNAS MADRINAS TARDÍAS}

La figura de las madrinas republicanas tuvo un desarrollo más tardío y fue bastante fugaz, posiblemente porque las mujeres desempeñaron un papel mucho más activo en la contienda. La presencia de las milicianas en los campos de batalla constituyó una novedad en Europa Occidental, aunque como ya se ha dicho, su eficacia fue más propagandística que bélica, según algunos.

21. Pilar Santamaría, ;Cuando los cañones duermen! Recuerdos nostálgicos de una madrina de guerra, edición de la autora, Burgos, 1981, p. 31.

22. M. de Ramón y C. Ortiz, Ibidem; p. 66.

23. M. de Ramón y C. Ortiz, Ibidem, p. 65.

24. F. Rodao, "Japón y la propaganda totalitaria en España, 1937-1945», en http:// www.florentinorodao.com/academico/aca98b.htm (Consultado el 15 de junio de 2015). 
El entusiasmo antifascista de los primeros días se tradujo en un gran número de milicianas que debería haber obtenido mejores resultados desde el punto de vista militar. Sin embargo, en la mayoría de los casos la falta de preparación militar de aquellas mujeres, al igual que les ocurrió a muchos hombres, limitó su capacidad de combate. Sobre todo si se compara con la experiencia de las aguerridas tropas del ejército de África que tenían enfrente.

En el Ejército Popular aparecieron muy pronto actitudes conservadoras que daban primacía al sexo masculino. La figura de la miliciana se vio muy pronto rodeada por una polémica que concluyó en 1936 con su alejamiento oficial de las trincheras para ocuparse de labores más tradicionales, aunque hubo algunas excepciones, como Elizaveta Parshina, una dinamitera rusa que luchó en el XIV Cuerpo de Guerrilleros del ejército republicano ${ }^{25}$ y más tarde en la II Guerra Mundial. Probablemente, las verdaderas mujeres-soldado de la época debieron de constituir una excepción.

En 1938 el alejamiento de las mujeres del frente se había consumado casi por completo. La revista Vida nueva, publicada en Jaén, hacía una serie de recomendaciones sobre el papel de la mujer en la guerra:

La mujer, en la retaguardia para ocupar hospitales, ya que la dulzura de la mujer no tiene rival para estos menesteres; en las guarderías infantiles, porque la mujer aunque no sea madre, el sexo le llamaba y sabe serlo; en las fábricas en los puestos mejores y de menor esfuerzo por su debilidad y estructura; y en las oficinas, en aquellos puestos en que pueda desarrollar una labor fructífera, siendo deber del hombre enseñarla y educarla, para que cuando a él le obliguen a dejar su puesto haya una mujer capaz de desempeñarlo ${ }^{26}$.

Una vez alejadas del frente y de la lucha directa, las mujeres republicanas comenzaron a alistarse en las «brigadas de reserva» que impulsaba el Partido Comunista. Su misión era estimular la actividad productiva en la retaguardia. El Comité Nacional de Mujeres contra la Guerra y el Fascismo organizó la participación femenina.

No obstante, ya en agosto de 1936 se había fundado la Comisión de Auxilio Femenino, que canalizó a las mujeres hacia la confección de uniformes y creó guarderías infantiles. Las defensoras de la República trabajaron también en las industrias bélicas y participaron en las tareas de fortificación. Asimismo algunas mujeres formaron en Madrid grupos de vigilancia contra los espías franquistas de la Quinta Columna.

En realidad, la participación en los ámbitos públicos y productivos parecía tener un carácter provisional, sólo hasta que volviesen del frente los hombres a los que habían sustituido y a los que «devolverían» sus puestos de trabajo. $\mathrm{Y}$ en esto coincidían con el destino de las mujeres nacionalistas. La colaboración

25. Elizaveta Parshina, La brigadista. Diario de una dinamitera de la Guerra Civil, Editorial La Esfera de los Libros, Madrid, 2002.

26. Francisco Cobo, «Los partidos políticos y las mujeres en la retaguardia republicana jienense (1936-39)», en III Jornadas sobre Las Mujeres y la Guerra Civil Española, Instituto de la Mujer, Salamanca, 1989, pp. 67-73. 
femenina en el esfuerzo de guerra tenía un horizonte temporal, aunque supusiera de hecho un paso hacia la emancipación. Este planteamiento ya se había dado en la Primera Guerra Mundial.

$\mathrm{Y}$ al igual que las mujeres franquistas, también las republicanas fueron madrinas de guerra, aunque mucho más tarde que aquellas. Comenzaron a aparecer hacia 1938, pero tuvieron un carácter muy distinto al de las madrinas nacionalistas. Mary Nash asegura que no se limitaban a escribir cartas y mandar paquetes, sino que también visitaban a los soldados en el frente, donde les hacían compañía, les lavaban la ropa y cocinaban ${ }^{27}$. Estas visitas solían enmarcarse en las "campańas de invierno" y permitían un contacto directo con los militares.

En realidad, y a pesar de los derechos que la Constitución republicana había reconocido a las mujeres, la figura de la madrina de guerra enlazaba con una visión tradicional que postergaba al sexo femenino al mismo papel secundario que las del lado franquista. Por el contrario, y a pesar de su fugacidad, la figura de la miliciana había aportado un ángulo innovador.

Salvo excepciones, la figura de la madrina de guerra republicana fue también muy breve. Se organizó muy tarde, hacia 1938, y desapareció antes de que terminase la guerra. Las autoridades leales liquidaron muy pronto esta práctica ante el temor de que hubiera filtraciones en beneficio del enemigo. Unas cortapisas que contrastan con el impulso continuo que la institución de las madrinas recibió del Gobierno de Burgos. Quizá por eso sea realmente difícil hablar de «institución», o quasi institución en la República en guerra, como sí ocurre con las nacionalistas.

Se han conservado pocas cartas de madrinas republicanas por la brevedad de su actuación y porque posiblemente al terminar la guerra, muchas madrinas y militares de la República destruirían esas cartas por miedo a que pudiese encontrarlas la policía del nuevo Estado. Aún así, Mary Nash reproduce algún pequeño fragmento en su libro.

Asimismo, en el relato publicado en Internet bajo el título "Cartes de un soldat republicá» aparece el dato de que Artur Inglés, un barcelonés que combatió en el Ejército Popular, tuvo una madrina de guerra llamada Teresa, que era amiga de una de sus hermanas ${ }^{28}$.

Tampoco los testimonios personales y familiares han aportado mucho. En unos casos porque «bastante había con trabajar y buscar comida en el Madrid sitiado como para dedicarse también a hacer de madrinas», según la frase de familiares próximos a este autor. El aviador republicano Joaquín Sáenz de Urturi afirmaba que «las madrinas de guerra fueron un invento de los nacionales». Aún así reconoció que en 1937 mantuvo correspondencia con una joven de Alcalá de Henares a la que «nunca llegó a considerar como su madrina» ${ }^{29}$.

27. Mary Nash, Rojas. Las mujeres republicanas en la Guerra Civil; Editorial Taurus, Madrid, 1999, p. 175.

28. J. Martínez y N. Rodríguez, "Cartes d'un soldat republicà»; en www.aasit.com/informatiu/ hemeroteca/marc/0042.htm (Consultado el 30 de enero de 2002).

29. M. de Ramón y C. Ortiz, Ibidem, p. 63. 
Y en este apartado cabría hablar también de las «madrinas de presos». Unas figuras que, de manera improvisada, protagonizaron varios casos entrañables de solidaridad con los soldados republicanos capturados durante la guerra que no podían recibir ayuda de sus familiares que se encontraban en la otra zona.

En Candás (Asturias), muchas jóvenes amadrinaron en 1937 a los republicanos encerrados en una fábrica convertida en campo de concentración. Las madrinas «cuidaban de ellos y se comunicaban por misivas clandestinas que arrojaban por las ventanas. Una vez en libertad los presos, iniciaron una vida en común»»3.

Y lo mismo hicieron algunas jóvenes de Villagarcía de Arosa (Pontevedra). Sus ahijados eran republicanos asturianos internados en el campo de concentración de Rianxo:

Se hizo en Villagarcía de Arosa una colecta para los prisioneros. Cruzaron la ría en una lancha y les llevaron ropa, castañas, nueces, vino, manzanas y calzado. En algunos bolsillos de esa ropa venían las direcciones de chicas que se ofrecían como "madrinas de guerra" de los prisioneros ${ }^{31}$.

C. Mir las denomina «madrinas de cárcel» y afirma que fueron «mujeres olvidadas entre las olvidadas, muchas de las cuales conocieron a sus maridos estando éstos en presidio y yendo ellas por ideología, convicción o simple humanitarismo, a brindarles ayuda y compañía ${ }^{32}$. Esta autora añade que el penal de Burgos «fue rico» en historias silenciadas de esta índole, según el testimonio de un ex preso.

\section{Una continuación lógica. Las madrinas españolas en la Segunda Guerra Mundial}

El Nuevo Estado franquista declaró a España oficialmente neutral en la Segunda Guerra Mundial, pero muchos españoles lucharon de forma individual en los ejércitos aliados y en los del Eje. Podemos pensar que se reprodujo a pequeña escala el enfrentamiento ideológico que hubo en la Guerra Civil. Casi podría hablarse de una nueva guerra civil dentro de la guerra mundial. Aunque rara vez los españoles llegarían a verse las caras en el campo de batalla, hay constancia de algunos choques en el frente de Leningrado entre patrullas de la División Azul y los guerrilleros comunistas dirigidos por el capitán Francisco Gullón.

30. David Orihuela, "Candás, 1937: Hoy, fallecido en el campo de concentración...», en $L a$ Nueva España (28/10/2002).

31. Sin Firma, «La libertad es un bien muy preciado. Campo de concentración de Rianxo (Pontevedra)", en www.asturiasrepublicana.com (Consultado el 17 de diciembre de 2001).

32. Conxita Mir, «La represión sobre las mujeres en la posguerra española» en Ángeles Egido y Matilde Eiroa (Eds.): Los grandes olvidados. Los republicanos de izquierda en el exilio, Centro de Investigación y Estudios Republicanos, Madrid, 2004, p. 214. 
Su misión era la de apoderarse de uniformes cogidos a patrullas españolas, infiltrarse en los capamentos divisionarios, recoger toda la información posible, captar a parte de la tropa en ese mismo momento o alentarla a desertar (...) es seguro que miembros de esta unidad y de otros destacamentos guerrilleros integrados por españoles y soviéticos llegaron a aproximarse mucho a su objetivo, pues disponemos de documentos sobre su captura por patrullas de la División ${ }^{33}$.

Una situación que no fue protagonizada exclusivamente por españoles. También se registró en muchos otros países donde se enfrentaron los partidarios de los gobiernos fascistas y de los demócratas (algunos de los ejemplos más conocidos son la lucha de los partisanos italianos contra los partidarios de Mussolini, la Francia Libre contra el régimen de Pétain o los guerrilleros yugoslavos de Tito contra las tropas del general Mihailovitch).

Muchos republicanos que habían salido de España tras la derrota se unieron a los ejércitos aliados para luchar contra los antiguos socios de Franco. Tanto en la Legión Extranjera francesa como en la Resistencia, hubo españoles que prosiguieron la lucha contra Alemania e Italia. El caso más conocido es el de la Nueve, la famosa compañía de la $2^{e}$ Division Blindée del general Leclerq, integrada casi por completo por soldados espańoles. Es de sobra conocido que los primeros tanques que liberaron París iban tripulados por antiguos republicanos que los habían bautizado con nombres de batallas de la Guerra Civil. También es sabido que los espańoles cumplieron su parte del trato, pero una vez terminada la contienda, los aliados se olvidaron de cumplir la suya y permitieron que la dictadura franquista continuara durante 40 años.

En esta contienda reapareció la figura de las madrinas de guerra y algunos combatientes españoles mantuvieron correspondencia con mujeres que en ciertos casos eran desconocidas y en otros eran incluso de su familia. Matilde del Valle actuó como madrina de su marido Fidel, pero también fue la madrina del capitán Juan Castillo. Ambos ahijados habían estado presos en el campo de concentración de Argelès-sur-Mer ${ }^{34}$.

La actriz Carlota Soldevila aseguraba a Núria Escur ${ }^{35}$ en una entrevista que durante el exilio de su familia en París tras la Guerra Civil, fue padrina de guerra $^{36}$ de un armenio al que movilizaron para luchar contra los alemanes. Soldevila afirmaba que «se dejó amar» por su ahijado y fa poc que he trencat les seves cartes $^{37}$.

La creación de la División Azul, conocida oficialmente como División Española de Voluntarios ofreció una nueva oportunidad a las antiguas madrinas

33. José Luis Rodríguez: De héroes a indeseables. La División Azul Editorial Espasa Calpe, Madrid, 2007, p. 290.

34. Denis Fernández-Recatalá, «Il y a soixante ans, la chute de la Republique espagnole entraînait un exode massif", en L'Humanité, 10 de abril de 1999; http: //site.voila.fr./espana36/ exil/retour99 (Consultado el 22 de mayo de 2002).

35. Nuria Escur: Escur, N: «Carlota Soldevila, el prestigio teatral». Entrevista en http://www.bcn.cat/publicacions/bmm/47/cs_entrev.htm, no consta la fecha (Consultado el 21 de junio de 2015).

36. En catalán no se dice madrina, sino «padrina».

37. «Hace poco que he roto sus cartas». 
franquistas para reanudar su actividad. Esta unidad militar no tenía ninguna relación orgánica con el ejército espańol. Estaba encuadrada en la Wehrmacht con el número 250 y constituyó un apoyo más o menos simbólico del nuevo régimen contra la Unión Soviética, a la que oficialmente seguía llamando Rusia.

Las autoridades franquistas volvieron a dar muchas facilidades para que los militares espańoles recibieran en la Unión Soviética las cartas de la retaguardia. El correo volvió a ser gratuito. No obstante, se produjeron roces con los mandos nazis debido al mal funcionamiento del Feldpost ${ }^{38}$, como afirma Vázquez Enciso, que incluso reproduce un escrito del coronel Manuel Estrada al teniente coronel Juan Roca de Togores, agregado militar en la Embajada de Espańa en Berlín:

Estoy seriamente preocupado por la manera de funcionar del correo particular. Las cartas de los familiares de la División Española de Voluntarios no llegan a los destinatarios. Son numerosísimas las quejas que recibo de personas que están alarmadas, pues en las cartas que de sus deudos reciben, estos les dicen que no han recibido ninguna noticia de Espańa desde su salida ${ }^{39}$.

Moreno Juliá afirma que la División Azul fue nuevamente «un mundo de hombres, pero la mujer tuvo un gran protagonismo, sobre todo desde una perspectiva indirecta de la mano de la Sección Femenina». Este protagonismo femenino se produjo en el frente con las enfermeras, pero también en la retaguardia con la labor de las madrinas de guerra:

Además, en clara mímesis con lo acaecido durante la Guerra Civil, muchas asumieron el papel de madrinas de guerra, prestas a mantener fiel correspondencia con la que paliar los rigores del frente. Es significativa, en este sentido, la labor de las muchachas de la colonia española en Italia vinculadas al falangismo, y de no pocas italianas ${ }^{40}$.

Un ejemplo de relación entre las madrinas y los divisionarios españoles se puede encontrar en el caso de Carmen Sánchez, que tras ser madrina de una treintena de militares en la Guerra Civil, prosiguió su tarea con varios divisionarios españoles en Rusia, según las cartas recogidas en libro ya citado Madrina de Guerra. Cartas desde el frente.

\section{LAS MADRinas DE GUERRA. TAN SOlO UNA BREVE HUELLA EN LA LITERATURA ESPAÑOLA}

Al comienzo de este trabajo, ya hemos podido comprobar como en la literatura francesa han quedado abundantes testimonios de la existencia de las

38. Correo militar alemán.

39. Manuel Vázquez, Historia Postal de la División Azul. Españoles en Rusia, Editorial Filatelia Hobby, Zaragoza, 1995, p. 85.

40. Xavier Moreno, La División Azul. Sangre española en Rusia, 1941-1945, Editorial Crítica, Barcelona, 2005, p. 396. 
madrinas. Por el contrario, en España hemos encontrado solo algunas pequeñas muestras, especialmente durante los años veinte, momento en que como se ha dicho, hay que pensar que aparecen las madrinas de guerra españolas.

En 1922, en plena Guerra de Marruecos, Miguel Mihura publicó La madrina de guerra: Comedia en dos actos ${ }^{41}$. Un par de años antes, José Martín ${ }^{42}$ había hecho una caricatura de esta clase de relaciones en Madrina de guerra, una novelita semanal que costaba 15 céntimos de peseta. En apenas 30 páginas, Martín crea un enredo en el que Félix Menéndez, un señorito de la ciudad, se hace pasar por su hermana Julia y comienza una relación postal con un soldado destinado en África. El militar se presenta en casa de su madrina durante un permiso y consigue seducir a la auténtica Julia, que termina deshonrada y huye con él.

En 1978, el poeta Manuel Ríos Ruiz obtuvo el Premio Ejército con su extenso poemario Cartas a una madrina de guerra. La obra de Ríos Ruiz contiene versos muy intensos:

Pero alegra vivir, madrina, clara, mascar el pan, verse el perfil en los cristales, volver a escribir, resucitar, decirte que te tuve siempre con los míos en la cabeza, que te soñé entre dolores y vómitos cuando más padecía y me agarraba a la fe, a la única buena salud y fortaleza, el arma recóndita y bravía que el soldado esgrime ${ }^{43}$.

En Madrina de guerra, Julián Gustem ${ }^{44}$ narra una difícil relación entre un soldado y una mujer que viven en zonas enemigas y se envían cartas por medio de un amigo inglés. Por su parte, la Oración de la madrina de guerra por su ahijado, obra de Pepe Urbano, comienza así:

\author{
Virgen Santa de la Peña \\ te ruego con devoción \\ le prestes tu protección \\ a mi ahijadito de guerra ${ }^{45}(2002)$
}

41. Miguel Mihura, La madrina de guerra: Comedia en dos actos, Editorial Viuda e hijos de R. Velasco. Madrid, 1922.

42. José Martín, Madrina de guerra, Publicaciones de La Revista Blanca, Barcelona, ca. 1920.

43. Manuel Ríos, "Cartas a una madrina de guerra", en La Memoria alucinada, Madrid, Editorial Calambur, 1998.

44. Julián Gustem, "Madrina de Guerra», Arena y Cal, núm 51, julio de 1999, en www.islabahia.com (Consultado el 19 de junio de 2015).

45. Fran, "Un homenaje a Pepe Urbano (ejemplo de sabiduría popular)», Fasnia en la red, www.fasnia.net/html/pepe6 (Consultado el 24 de enero de 2002). 


\section{Conclusiones}

En términos materiales, y desde un punto de vista militar, la figura de la madrina de guerra supuso una aportación de las mujeres inferior a la labor que realizaron las enfermeras o las trabajadoras de las industrias de armamento. Sin embargo, su tarea fue también muy apreciable por el apoyo moral que prestaron a los combatientes.

Las madrinas de guerra ejercieron el doble papel de relacionarse con los hombres que estaban en el frente y, al mismo tiempo, mantener la comunicación entre la sociedad civil de la retaguardia y los soldados.Y tal vez muchas de ellas ni siquiera fueron conscientes de este segundo cometido.

Desde el punto de vista de la liberación de la mujer, el papel de la madrina de guerra pudo constituir un paso atrás, porque contribuyó a encasillar a la mujer en el mundo de las tareas domésticas tradicionales.

El ejército franquista apoyó de manera decidida a las madrinas, cuya labor fue considerada como una especie de «deber patriótico» para las mujeres.

Por el contrario, en la zona republicana, y salvo iniciativas individuales, las madrinas aparecieron muy tarde, en torno a 1938. Por tanto, su actividad duró muy poco. Este retraso pudo deberse al papel mucho más activo que desempeñaron las mujeres en esa zona, primero como milicianas y después trabajando en la retaguardia. Según algunos testimonios personales, las difíciles condiciones de vida en las ciudades republicanas impidieron que muchas jóvenes actuasen como corresponsales de los soldados. Las madrinas republicanas, a diferencia de las nacionalistas, escribían menos cartas, pero acudían con más frecuencia a los frentes para atender a los soldados. 
